\title{
BIOLOGIA POPULACIONAL DO CARANGUEJO CHAMA-MARÉ MINUCA RAPAX (SMITH, 1870) (DECAPODA: OCYPODIDAE: GELASIMINAE) EM UM MANGUEZAL HIPERSALINO NO NORDESTE BRASILEIRO
}

\author{
Guizardi, P.S. ${ }^{1,}$; Fortaleza, M.O. ${ }^{1}$ \& Bezerra, L.E.A. ${ }^{1}$ \\ ${ }^{1}$ Universidade Federal do Ceará (UFC), Instituto de Ciências do Mar, Laboratório de Zoobentos. \\ *Autor correspondente: polianasalve@gmail.com
}

\begin{abstract}
Minuca rapax é uma das nove espécies de caranguejo "chama-maré" que ocorre nos manguezais do nordeste brasileiro. O objetivo deste trabalho foi estudar aspectos populacionais (razão sexual, estrutura etária, maturidade sexual, períodos de recrutamento e reprodutivo) de M. rapax no manguezal do Rio Pacoti, Eusébio, Ceará. As coletas foram mensais, de janeiro de 2016 a dezembro de 2017, utilizando-se o método de captura por unidade de esforço (CPUE), onde todos os indivíduos encontrados sobre a superfície do solo foram coletados manualmente por um único coletor, durante uma hora. Os indivíduos foram sexados e mensurados quanto à largura da carapaça (LC), comprimento do maior quelípodo e largura do abdome $( \pm 0,01 \mathrm{~mm})$. Teste Quiquadrado foi usado para verificar se a razão sexual encontrada diferia da proporção esperada (1:1). Teste $t$ de Student foi realizado para comparar o tamanho médio dos indivíduos de cada sexo. A estrutura etária foi analisada em função da distribuição por classe de tamanho (amplitude de $2 \mathrm{~mm}$ de LC). A maturidade sexual morfológica foi calculada usando a técnica de alometria. Os períodos de recrutamento e reprodutivo foram determinados com base na frequência mensal de juvenis e fêmeas ovígeras, respectivamente. Foram coletados 1858 indivíduos, sendo 1108 (59,6\%) machos, 735 (39,6\%) fêmeas, destas 15 (0,8\%) estavam ovígeras e 15 $(0,8 \%)$ juvenis com sexo indeterminado. A razão sexual (M:F) total foi 1,5:1, diferindo significativamente entre os sexos $(p<0,05)$. Machos foram significativamente maiores do que as fêmeas $(p<0,05)$. O tamanho dos machos variou de 2,24 a 25,44 mm de LC (14,84 $\pm 4,54 \mathrm{~mm}$; média \pm DP), com predominância nas classes de 8 a $22 \mathrm{~mm}(52,6 \%)$. Fêmeas variaram de 3,56 a 21,72 mm, sendo mais abundantes de 8 a $18 \mathrm{~mm}(31,5 \%)$. A menor fêmea ovígera apresentou 13,94 mm. O tamanho da maturidade sexual foi de 11,92 $\mathrm{mm}$ para machos e 11,50 mm para fêmeas. Por meio do cálculo da maturidade sexual, foi possível separar adultos e juvenis, sendo $317(17,1 \%)$ machos juvenis e 278 (15\%) fêmeas juvenis. O recrutamento foi contínuo, porém, a maior frequência desses juvenis foi observada em junho e agosto de 2016 e de junho a outubro de 2017. Fêmeas ovígeras foram coletadas em fevereiro $(n=4)$ e junho $(n=1)$ de 2016 e maio $(n=10)$ de 2017, meses com altos índices pluviométricos, com exceção de junho. Desta forma, o regime de chuvas influencia o ciclo reprodutivo da espécie, sendo observado um maior recrutamento no final desse período.
\end{abstract}

Palavras-chave: caranguejo violinista, CPUE, gênero Minuca. 